\title{
PERFORMANCE OF ICE SLURRY GENERATOR WITH MECHANICAL SCRAPER USING R-22 AND R-290
}

\author{
Fajri A. Rayhan ${ }^{1}$, Agus S. Pamitran ${ }^{1 *}$ \\ ${ }^{1}$ Department of Mechanical Engineering, Faculty of Engineering, Universitas Indonesia, Kampus UI \\ Depok, Depok 16424, Indonesia
}

(Received: January 2017 / Revised: May 2017 / Accepted: December 2017)

\begin{abstract}
Ice slurry technology is highly favored to maintain the freshness of fish, as the cooling capacity of ice slurry is higher than that of flaked ice, tubular ice, plate ice, and block ice. One important part of an ice-slurry system is the ice generator. A mechanical scraper is the easiest type of iceslurry generator to fabricate, because mechanical scrapers use only one type of material, such as stainless steel. The purpose of this research was to develop a prototype ice-slurry generator and analyze its performance. To enable comparison of their performance, both the R-22 and R-290 refrigerants were used as the working fluids in the refrigeration system. The study observed the time necessary to form ice and the scraper's ability to scrape the ice on the inner surface of the evaporator. The best system included faster ice-slurry generation and a durable generator that did not freeze up. Four combinations of scraper RPM and pump RPM varied speeds from low to high. The results showed that using R-290 refrigerant and lower RPM speeds for both the scraper and the pump generated ice slurry in a shorter time.
\end{abstract}

Keywords: Ice slurry; Mechanical scraper; R-22; R-290; Sea water

\section{INTRODUCTION}

The fishing industry is one of the largest assets possessed by maritime nations. Indonesia, as an archipelagic nation, contains more than 18,000 islands and has about $81,000 \mathrm{~km}$ of coastline, which, according to data from the Geospatial Information Agency, is the second-longest coastline in the world, after Canada. Based on data from the Ministry of Fisheries Indonesia, the nation had the potential to develop a fishing industry of up to 6.5 million tons in 2014 (KKP, 2014).

To support the fishing industry's potential, technology to preserve the fish is necessary. There are many types of fish preservation, one of which is ice-slurry technology, which has been the subject of much research. Ice-slurry technology has many advantages: it can keep fish fresh for six days without damaging the meat (Kitamurai et al., 2015), it provides high thermal density storage, and it has a fast cooling rate. Ice slurry has advantages over traditional single-phase fluids; however, applying ice slurry poses many challenges (Hernández et al., 2013).

An ice-slurry generator is a heat-exchange apparatus that produces ice slurry using various types of solutions, and it works by using the basic principles of the refrigeration cycle. Generally, there are many types of ice-slurry generators (Egolf \& Kauffeld, 2005).

One that has been widely accepted over the last 20 years and that is currently used by many

*Corresponding author's email: pamitran@eng.ui.ac.id, Tel. +62-21-7270032, Fax. +62-21-7270033

Permalink/DOI: https://doi.org/10.14716/ijtech.v8i7.686 
researchers is an ice-slurry generator that uses a mechanical scraper (Kauffeld et al., 2005). Modifications to the various forms of this scraper have been made to increase the efficiency of grinding the layer of ice that accumulates on the walls of the heat exchanger, thereby optimizing the system's operation.

The present study developed an ice-slurry generator that had a mechanical scraper. Sea water was used as a solvent to generate the ice slurry (Melinder, 2010) because sea water is a natural resource directly accessible to fishermen. The present study compared the performance of R290 and R-22 as working fluids for the refrigeration system.

\section{EXPERIMENTAL METHODS}

\subsection{Data Collection}

Figure 1 shows the data-collection process. The generator was designed using type 316 stainless steel. The system included a condensing unit, an electric motor, a magnetic pump, and an inverter. After installation, the tools, including the digital thermometer, infrared thermometer, and pressure gauge, were checked and caliberated.

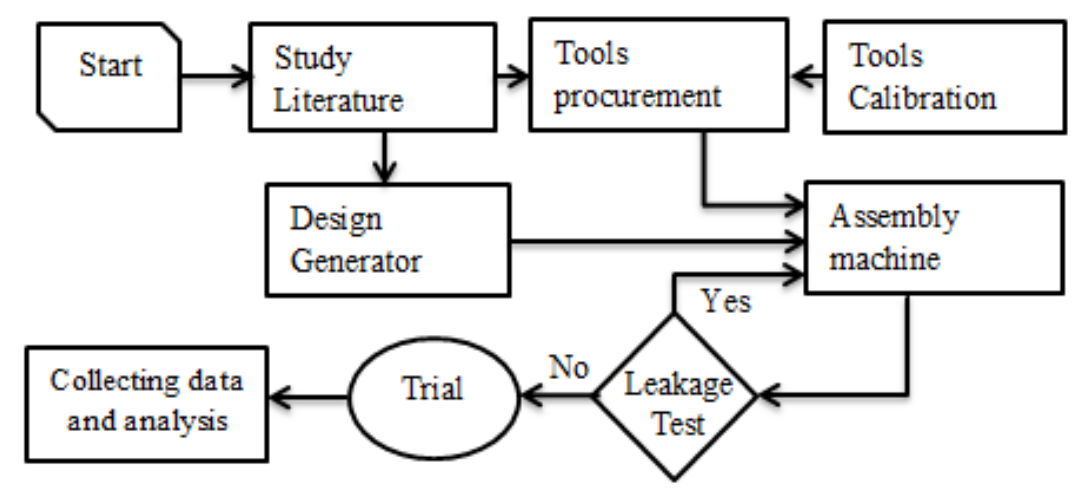

Figure 1 Schematic of methodology

Other components were also checked, including the electrical components; the copper pipes and sea water pipes, which were leakage tested; and the vacuum system. Trials were conducted to observe the effects of various combination of pump and motor RPM speeds on the following: decreasing the temperature of 5 liters of sea water, the time necessary to form the ice slurry, the density of the ice slurry, and the power required. The data obtained during the test were processed and analyzed in graphical form.

\subsection{Experimental Device and Ice-slurry System}

The working principle of an ice-slurry generator is similar to that of a heat exchanger having a concentric tube consisting of 2 tubes of different diameters but of the same height, one inside the other. In the outer tube, refrigerant flows at a low pressure with a saturation phase, causing a convection process that absorbs heat into the wall of the inner tube, necessitating that the wall of the inner tube be cooled by a refrigerant. The material selected for both tubes was type 316 stainless steel, which can withstand the oxidative effects of corrosive solutions, such as sea water, which has salinity of 30 parts per thousand. Figure 2 shows the design of the ice slurry's generator.

Continuous circulation of seawater in the generator will result in the build-up of ice on the wall of the inner tube. The layer of ice significantly reduces the thermal conductivity of the inner tube, because the ice has great heat resistance. If the ice is allowed to build up on the generator, the flow of the solvent in the generator will slowed. Therefore, an additional apparatus is needed to grind the ice off of the generator's inner walls. 


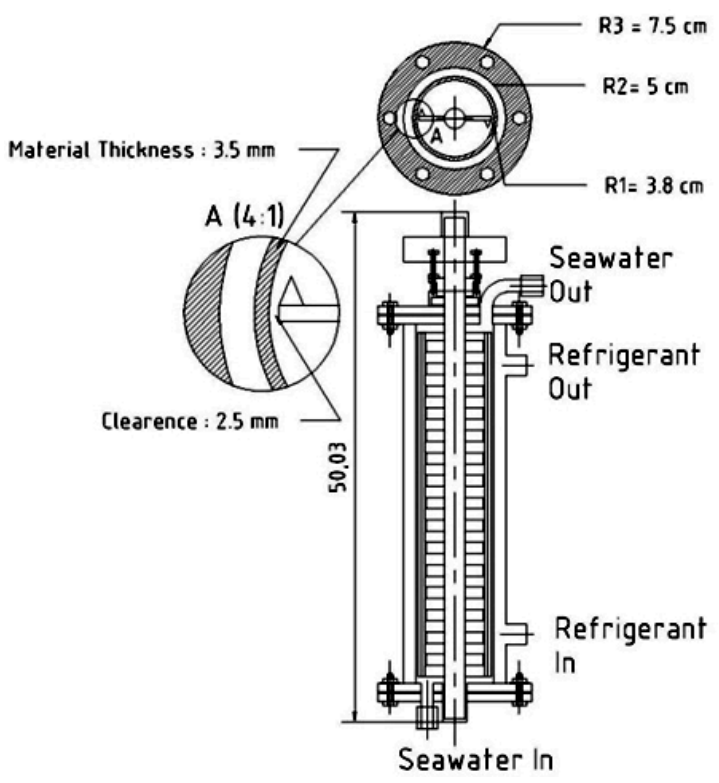

Figure 2 Ice-slurry generator with two symmetric blades

A scraper is a shaft having blades that added to the generator to prevent ice from accumulating on the wall of the inner tube and to maintain the homogeneity of the solution. The optimal scraper design uses 2 symmetrical blades with a $2.5-\mathrm{mm}$ clearance from the wall of the inner tube (Lakhdar et al., 2005). To prevent sea water from leaking in at the top, the shaft's leverage used Teflon as gland packing. Teflon was used because it has the lowest coefficient of friction of all solid materials. Hence, the rotation of the generator's shaft had no significant frictional resistance (Constantinou et al., 1990). A split condensing unit had 368 watts of power. The system used a rotary compressor containing 2 helical screws that produced compressed air in large quantities, because R-290 needs greater compression power than R-22. Pressure gauges were located at 4 points: the inlet evaporator, inlet compressor, inlet condenser, and inlet expansion valve). The system used a ball valve, which can be adjusted manually, as the expansion valve. Figure 3 shows a schematic of the installed equipment.

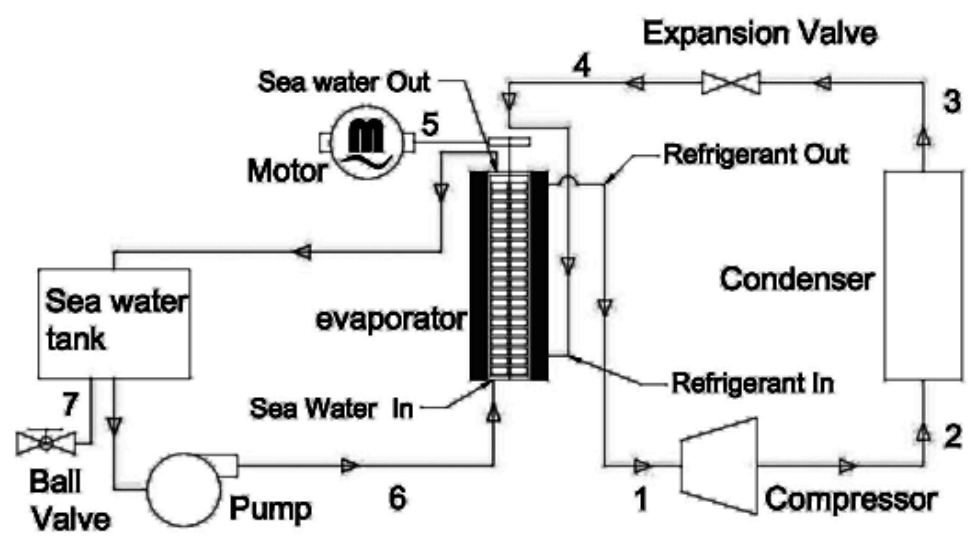

Figure 3 Schematic of ice slurry system

A centrifugal-type magnetic pump is compatible with ice slurry and can be used for 1000 hours without encountering problems (Frei \& Huber, 2005). This system used a magnetic pump hat had 45 watts of power and a flow rate of 40 liters $/ \mathrm{min}$. The magnetic pump is augmented by use of an inverter to adjust the flow rate of the solution. An electric motor moved the generator's shaft, which was connected by a pulley and belt. The electric motor used had a power 
specification of $1 \mathrm{HP}$ and 3 input phases. Like a magnetic pump, an electric motor uses an inverter to adjust its rotation. The use of a refrigerant can affect the properties of ice slurry (Kauffeld et al., 2010). The present study compared the performance of R-22 and R-290 as refrigerants. Table 1 shows the properties of the two.

Table 1 Comparison of R-22 and R-290 (Wang \& Wang, 2000)

\begin{tabular}{lcc}
\hline Refrigerant & $\mathrm{R}-22$ & $\mathrm{R}-290$ \\
\hline Name & Chlorodifloromethane & Propane \\
Formula & $\mathrm{CHClF}_{2}$ & $\mathrm{C}_{3} \mathrm{H}_{8}$ \\
Flash Point & Nonflammable & Flammable \\
Odor & Sweetish & Odorless \\
Molar Mass & $86.47 \mathrm{~g} / \mathrm{mol}$ & $44.1 \mathrm{~g} / \mathrm{mol}$ \\
Melting Point & $-175.42^{\circ} \mathrm{C}$ & $-187.7^{\circ} \mathrm{C}$ \\
Boiling Point & $-40.7^{\circ} \mathrm{C}$ & $-42^{\circ} \mathrm{C}$ \\
GWP & 1700 & 3 \\
ODP & 0.055 & 0 \\
\hline
\end{tabular}

\section{RESULTS AND DISCUSSION}

Under ambient conditions, the temperature of sea water is $27^{\circ} \mathrm{C}$. Because sea water is a fluid that will turn into ice slurry, the present study applied it to the ice generator. The sea water's temperature decreased until it formed ice slurry at $-2^{\circ} \mathrm{C}$. The present study began recording experimental data regarding sea water temperature at $15^{\circ} \mathrm{C}$ and continued until the sea water formed ice slurry. The study also compared the results of using R-22 and R-290 in the refrigeration system. To provide similar conditions for the two refrigerants, a low pressure (2 bar) was maintained for both refrigerants. In addition, the study varied the RPM speeds of both the pump and motor from low to high to observe the influence of speed on decreasing the temperature of the sea water. The pump's impeller rotations were 1480, 1777, 2074, and 2371 RPMs. The scraper's rotations were 486, 557, 646, and 737 RPMs. Figures 4 and 5 show the values measured for the decreasing temperature of the sea water.
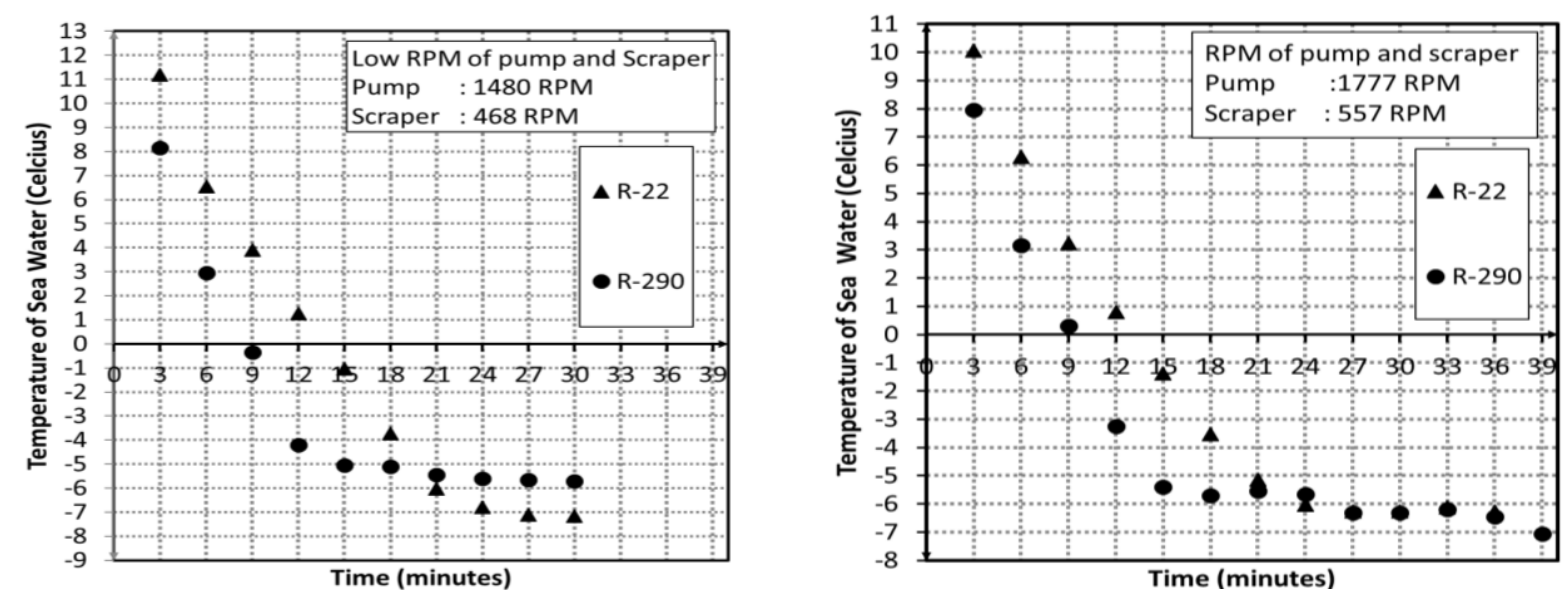

Figure 4 Graphs of sea water degradation temperature with 1480 RPM for pump and 468 RPM for motor (left) and 1777 RPM for pump and 557 RPM for motor (right)

Overall, the results of the data showed that the higher the RPM speed of the scraper, the longer it took to generate ice. Although this higher speed required a longer time to generate ice, it helped maintain the performance of the scraper, preventing its sudden cessation. In addition, 
when the scraper speed was higher, the process of transferring heat to the evaporator was more even, and a higher speed enabled the scraper to continue grinding the ice layer that built up on the inner walls of the evaporator.

The data regarding the R-22 refrigerant indicated that a sudden cessation of the scraper could be caused by the accumulation of ice in the generator. When R-22 was used as the refrigerant, the ice slurry was generated the fastest when the speeds of both the pump and scraper were higher, 2371 RPM and 737 RPM, respectively. At these speeds, it took 18 minutes for ice slurry to be generated from sea water that had an initial temperature of $15^{\circ} \mathrm{C}$.

In contrast, when R-290 was used as the refrigerant, the scraper was kept rotating with no sudden cessations, and the ice slurry was generated the fastest when the speeds of both the pump and the scraper were slower, 1480 RPM and 468 RPM, respectively. At these speeds, it only took 13 minutes to form ice slurry.

Regarding the efficiency of the two refrigerants, when R-22 was used as the refrigerant, all five liters of sea water could not be converted into ice slurry, and only a small volume of ice slurry was generated. In contrast, when R-290 was used as the refrigerant, all five liters of sea water were converted into ice slurry, demonstrating the superior ability of the R-290 refrigerant to absorb heat from the sea water.
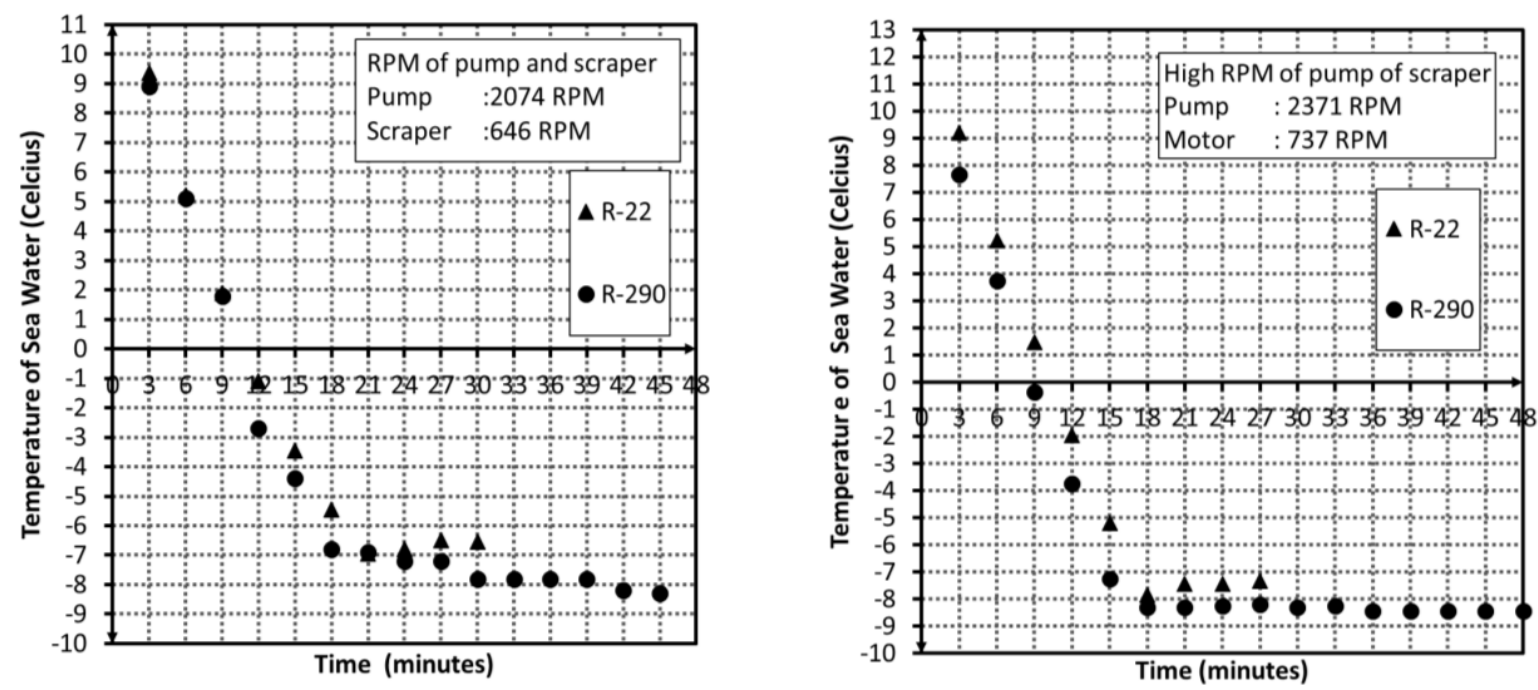

Figure 5 Graph of temperature decrease in sea water at 2074 RPM speed for pump and 646 RPM speed for motor (left) and at 2371 RPM speed for pump and 737 RPM speed for motor (right)

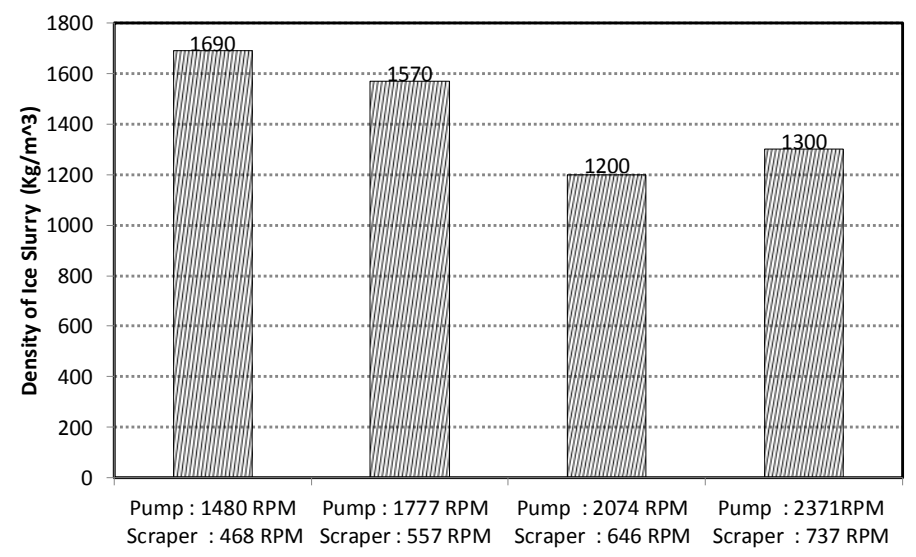

Figure 6 Effects of pump and scraper RPM speeds on ice-slurry density 
In addition, the data showed that the higher the RPM speed of the pump, the faster the temperature of the sea water decreased. This can be explained by the fact that the higher pump speed increased circulation of the sea water in the evaporator, causing the heat from the water to be absorbed more quickly. In contrast, faster RPM speeds of both the pump and the scraper resulted in less dense ice slurries, as shown in Figure 6.

\section{CONCLUSION}

The present study investigated the performance of an ice-slurry generator having a mechanical scraper. The results showed that a higher scraper speed and a constant pump speed took longer to produce ice slurry than did a lower scraper speed but had the advantage of maintaining scraper performance without sudden cessations. In contrast, a higher pump speed and a constant scraper speed decreased the temperature of sea water more quickly. In addition, the results indicated that R-290 was a more efficient refrigerant than R-22, efficiently lowering the temperature of more sea water, enabling ice scraping, and avoiding generator freezing.

\section{ACKNOWLEDGEMENT}

This study was funded by a grant from Fundamental RISTEKDIKTI, Number : 2566/UN2.R3.1/HKP05.00/2017

\section{REFERENCES}

Constantinou, M., Mokha, A., Reinhorn, A., 1990. Teflon Bearings in Base Isolation II: Modeling. Journal of Structural Engineering, Volume 116(2), pp. 455-474

Egolf, P.W., Kauffeld, M., 2005. From Physical Properties of Ice Slurries to Industrial Ice Slurry Applications. International Journal of Refrigeration, Volume 28(1), pp. 4-12

Frei, B., Huber, H., 2005. Characteristics of Different Pump Types Operating with Ice Slurry. International Journal of Refrigeration, Volume 28(1), pp. 92-97

Hernández, M., Sebastián, D., Fernández, S., Pedro, J., Gómez, I., Fernando, Robles, V., Antonio, 2013. Production of Ice Slurry in a Scraped-Surface Plate Heat Exchanger. Available online at http://hdl.handle.net/10317/4572, Accessed on March 21, 2017

Kauffeld, M. Wang, M.J., Goldstein, V., Kasza, K.E., 2010. Ice Slurry Applications. International Journal of Refrigeration, Volume 33(8), pp. 1491-1505

Kauffeld, M., Kawaji, M., Egolf, P.W., 2005. Handbook on Ice Slurries. International Institute of Refrigeration, Paris, 359

Kitamurai, K., Matsumoto, Y., Uno, M., 2015. Introduction of Ice Slurry Producing Apparatus Capable of Making Ice from 1wt\% Salinity. Journal of Fishing Boat and System Engineering Association of Japan, pp. 2-3

Kementrian Kelautan dan Perikanan (KKP), 2014. Performance Reports of Marine and Fisheries Ministry Indonesia. Jakarta

Lakhdar, M.B., Cerecero, R., Alvarez, G., Guilpart, J., Flick, D., Lallemand, A., 2005. Heat Transfer with Freezing and a Scraped Surface Heat Exchanger. Applied Thermal Engineering, Volume 25(1), pp. 45-60

Melinder, A., 2010. Properties and Other Aspects of Aqueous Solutions Used for Single Phase and Ice Slurry Applications. International Journal of Refrigeration, Volume 33(8), pp. $1506-1512$

Wang, S.K., Wang, S.K., 2000. Handbook of Air Conditioning and Refrigeration. New York: McGraw-Hill 